\title{
Virtual Reality Software as Preparation Tools for Oral Presentations: Perceptions From the Classroom
}

\author{
Mohamed J. Alsaffar \\ Saint Michael's College, Vermont, USA
}

\begin{abstract}
Although there is a wealth of studies on the role of virtual reality (VR) technology in language acquisition, little research has been done on the utilization of virtual reality mobile applications in English language acquisition, especially in developing oral presentation skills. The main purpose of this case study is to investigate the usefulness of VirtualSpeech, which is a virtual reality mobile application, as a preparation tool for oral presentations via the perceptions of international students and their instructor. The participants are five Academic English Program (AEP) students and their English language instructor at Saint Michael's College. Qualitative analyses were performed on data collected from: (1) learning logs that were shared between the students and the researcher, (2) surveys that were sent to the students and their instructor, (3) one-to-one interviews with the students, and (4) the researcher's fieldnotes of the students' oral presentation performances. The results of the study show that all of the participants recommend using VirtualSpeech as a tool to prepare for oral presentations. Most of the students reported higher confidence levels while speaking English after their use of VirtualSpeech. Thus, this case study can be considered as a contribution to the research on VR mobile applications in English language acquisition.
\end{abstract}

Index Terms-virtual reality, oral presentation, public speaking anxiety, English language learners, VirtualSpeech

\section{INTRODUCTION}

As digital platforms become ubiquitous components of educational environments, there is an increasing interest in more advanced digital tools. One such tool is virtual reality (VR), the use of computer programs and purpose-built video-display headsets to simulate an artificial environment (Schroeder, 1996). With large companies investing hundreds of millions of dollars into new generations of VR technology (Molla, 2017), its capabilities have grown rapidly and there are now a number of VR-based educational systems available, which are seeing some use in classrooms. In particular, VR programs have been developed to assist the outcomes of language learning curricula (Li \& Wong, 2021), with simulated environments and interactions used to augment standard in-classroom activities.

Moreover, VR may be especially promising for tackling particular kinds of educational challenges. One of these is public speaking anxiety (PSA), a common anxiety disorder that affects approximately $40 \%$ of those who suffer from social phobias (Ruscio et al., 2008). There is evidence that exposure to the sources of phobias in virtual environments can provide safe and effective means of combating fear and easing anxiety through a gradual process of familiarization (Owens \& Beidel, 2015; Wallach et al., 2009). In the classroom, VR applications that allow students to practice public speaking while remaining in private-addressing only a virtual audience — offer great means of helping people overcome PSA gently (Hinojo-Lucena et al., 2020; Stupar-Rutenfrans et al., 2017). The present study takes up this issue, building on previous work that has examined the use of VR applications in second language acquisition for English language students.

\section{LITERATURE REVIEW}

The first section introduces the concepts of virtual reality environments (VREs) and virtual learning environments (VLEs) and reviews research on the use of VREs and VLEs in the field of English language learning. The second section reviews research on the application of VLEs in combating anxiety, specifically public speaking anxiety.

\section{A. Virtual Reality in Language Education}

Learning a language is a complex endeavor that requires mastering not only vocabulary and grammar but also skills and habits for producing, receiving, and handling information more generally (Burns \& Joyce, 1997). In speaking a new language, the learner has to learn new words and naming patterns that can be different from the learner's first language (Pavlenko, 2011). Thus, second language learners face multiple challenges simultaneously, as they need to adapt to different components of speaking skills, which are vocabulary, grammar, fluency, pronunciation, and comprehension (Harris, 1969; Syakur, 1987). Learners overcome these challenges by using innovative strategies with common examples, including acting out a script, communication games such as information-gap and role-play, discussions such 
as formal debates, and prepared talks such as oral presentations (Harmer, 2007). Oral presentations are especially helpful, as they offer a stable scaffold to organize speech — typically a set of slides or notes - and a unidirectional communicative mode that allows students to focus on their linguistic performance without the need to practice language comprehension at the same time (Hyland, 1991; Nation \& Newton, 2008).

Presentations delivered in simulated environments may even be more effective, as simulations can provide easily accessible and low-stakes means of practicing real-world behaviors or skills (Banks et al., 2001; Merchant et al., 2014; Page \& Smith, 1998). Such simulations are common training tools across many fields-for instance, one common example is Microsoft Flight Simulator, which allows its users to control virtual aircraft with a high degree of real-world validity (Beckman, 2009).

In educational contexts, simulated or "virtual reality environments" (VREs) are a means of giving complex visual, auditory, and interactive feedback in the absence of the real-world circumstances that would typically be required (Brundage \& Hancock, 2015; Olle \& Westcott, 2018). Most virtual environments also include game-like elements or are themselves videogames, making them engaging, motivating, and appealing to students of all ages (Gee, 2007; Kirriemuir \& McFarlane, 2003; Tobias et al., 2014). VREs can very easily be designed so that the skills they encourage are education-relevant, such as problem-solving, learning strategies, or interactional skills (Ang \& Krishna, 2008; Chen \& Hsu, 2020; Gee, 2003).

Some recent work has explored the use of VREs as tools in language learning. In one study, conducting lessons and activities with English language learners (ELLs) in virtual environments in online games such as Second Life (Linden Lab, 2003) was found to improve vocabulary development (Hsiao et al., 2017). Students may also feel more creatively free, better able to communicate easily, and more comfortable following instructions while learning in VREs rather than physical classroom settings (Cheng et al., 2017; Reinders, 2012). These results are significant in light of the global prevalence of English as a second language, as it is the most widely spoken and frequently taught second language in the world. Thus, techniques that facilitate ELL instruction have the potential to increase the efficiency of instruction for a large number of students (Young et al., 2012). Moreover, students tend to prefer VREs to more traditional learning aids, such as textbooks (Lin \& Lan, 2015; Symonenko et al., 2020).

The reasons behind the utility of VR tools in language classrooms have also been explored. This is because the design of virtual environments is so flexible and relatively unconstrained by limitations such as physical space; therefore, VR technology allows the instructor to design virtual environments (e.g., virtual classrooms) that promote verbal and physical interactions that are most relevant to the language skills being taught (Cheng et al., 2017; Morrison, 2017). Thanks to this flexibility, VR learning can be integrated with task-based language teaching (TBLT) to create virtual learning environments (VLEs) that foster collaboration, autonomy, and communication skills. Moreover, these VLEs are able to accommodate students with specific learning needs (Lin \& Lan, 2015). Ruggiero (2013) points to another benefit: VLEs allow students to exercise their skills and practice content knowledge in "fail-safe situations." Fail-safe situations are learning contexts in which students feel safe to make mistakes related to language usage, and they avoid any possible embarrassment due to miscommunication. These properties of VLEs highlight their potential to alleviate language learning challenges such as social inhibition and anxiety by providing low-stress contexts for language practice.

\section{B. Anxiety and Virtual Reality in Educational Contexts}

The potential that VLEs possess to help alleviate anxiety is a significant advantage. Woodrow (2006) writes that, "anxiety experienced in communication in English can be debilitating and can influence students' adaptation to the target environment and ultimately the achievement of their educational goals" (p. 309). Many students experience extreme anxiety when delivering oral presentations, which - given the negative effects of anxiety on memory and attention - naturally hinders learning (King, 2002). In general, emotions significantly influence cognitive functions such as perception and memory (Parkinson et al., 1996), thereby affecting learning (Pekrun et al., 2002). Immordino-Yang explains the relationship as follows:

Emotions are not add-ons that are distinct from cognitive skills. Instead emotions, such as interest, anxiety, frustration, excitement, or a sense of awe in beholding beauty, become a dimension of the skill itself. This is one reason that anxiety can be so debilitating to students' performance. (Immordino-Yang, 2015, p. 21)

Many individuals live with one or more social phobias, of which public speaking anxiety (PSA) is among the most common. PSA can be debilitating, causing fear-based fantasies of failure and embarrassment and distracting learners from the task or activity at hand (Pertaub et al., 2002). It can lead to students performing poorly, refusing to speak in class, or, in extreme cases, dropping out of school (Harris et al., 2002). These issues may be exacerbated for students who are primarily familiar with highly teacher-focused classrooms in many Asian countries (King, 2002).

There are a number of ways to confront anxiety disorders and non-clinical anxiousness. Leading clinical tools include traditional cognitive behavioral therapy (CBT), which is a clinically proven psychotherapy that successfully helps in changing patients' behavior and thought pattern (Beck, 2011). Moreover, several meta-analyses about CBT treatment concluded that CBT is efficacious in treating anxiety disorders (Otte, 2011). Another alternative to CBT is direct exposure therapy (EXP), which involves desensitizing patients from fear-inducing stimuli through safe, mild, and controlled exposure (Myers \& Davis, 2007). However, Owens and Beidel (2015) argue that - especially in non-clinical settings - a virtual version of EXP might be both more ethical and far easier to practice. Owens and Beidel dub this 
method "virtual reality exposure therapy" (VRET), and it has proven effective in reducing anxiety-related symptoms in a wide range of circumstances (Opriş et al., 2012; Powers \& Emmelkamp, 2008; Stupar-Rutenfrans et al., 2017; Wallach et al., 2009). Moreover, researchers such as Reeves (2020) conducted a meta-analysis study on the use of VRET in combating public speaking anxiety, which generally found that VRET significantly decreases the symptoms of PSA.

In the specific context of language learning, and even more narrowly the use of oral presentations to practice speaking skills, several VR applications are available. These include Be Fearless: Fear of Public Speaking (Samsung, 2016) and Speech Trainer (Wolf in Motion, 2016), both of which aim to enhance ELLs' capabilities in public speaking and to lower their PSA. Additionally, recent studies recommend instructors to adopt VR as a new and innovative approach in speech preparation, as it is efficient in increasing students' confidence in public speaking and can be effectively incorporated into the classroom (Frisby et al., 2020; Hinojo-Lucena et al., 2020; Lindner et al., 2021).

This under-explored relationship between VR and anxiety presents an opportunity for the widespread use of VR in classrooms to allow students to access the benefits of oral presentations as part of second language acquisition. This is because speech is essential to all forms of social engagement; moreover, adults are frequently judged on their speaking skills, and the acquisition of high levels of speaking skills can assist individuals in achieving personal goals (Bygate, 1987; Thornbury, 2005). This makes public speaking skills an essential educational outcome; combined with the potential for anxiety reduction, the case for the use of VR in ELL environments is clear.

\section{METHODS}

This case study was conducted to investigate the usefulness of VirtualSpeech as a preparation tool for oral presentations via the perceptions of AEP students and their instructor. The study utilized qualitative methods to answer the following research questions:

1. Having used VirtualSpeech as a preparation tool for oral presentations, how do students describe their emotional state in presentations?

2. What value do students see in VirtualSpeech as a preparation tool for presentations?

3. What value does the instructor see in VirtualSpeech as a preparation tool for presentations?

\section{A. Research Design}

This case study was conducted in a 16-week AEP oral skills course at Saint Michael's College in Vermont. The course aimed to improve learners' English speaking and listening skills through listening activities, class discussions, and oral presentations. The students had to do two presentations which were among the main assessment methods of the course. The first presentation occurred in the middle of the semester and was called the midterm presentation, while the second one occurred in the last days of the semester and was called the final presentation. The researcher provided the participants with a Google Cardboard headset before they did the midterm presentation. Regarding the employed research methods, the researcher conducted interviews with the students, wrote observations of students while they were delivering presentations, distributed surveys to the students and their instructor, and individually shared a private Google Document with each participating student in order to log the student's use of VirtualSpeech before the midterm presentation.

\section{B. Participants}

There were seven students in the AEP oral skills course, and all of them are native Chinese speakers who initially agreed to participate in the study of this research. However, after the first measure of data collection, which is learning $\operatorname{logs}$, the researcher withdrew the participation of two students due to reasons which are explained below. Consequently, five participating students were included in all of the qualitative measures of the study. In this group of five students, there were four males and one female, and they were between 20 and 22 years old. All of the student participants were Academic English Program (AEP) students, and all of them were enrolled in AEP after achieving satisfactory progress in the Intensive English Program (IEP) at Saint Michael's College. Generally, AEP students have TOEFL scores that range between 61-78 for the Internet-based Test (iBT) format of the TOEFL test. Regarding the instructor, the instructor's areas of expertise include academic English, presentation skills, speaking and listening, and computerassisted language learning (CALL). Furthermore, the instructor's first language is American English. In order to preserve the confidentiality of the participants, all participating students were assigned an identification code (e.g., P1 was assigned for a participating student).

\section{Instruments}

The instruments used in the case study were the Google Cardboard VR device, VirtualSpeech VR application, learning logs via Google Docs, surveys via SurveyMonkey, one-to-one interviews, and the researcher's fieldnotes.

\section{Google Cardboard}

Most VR programs rely on cumbersome and expensive headsets that can only be run by high-end personal computers, making them inefficient for most classroom environments. However, there are alternatives. One of the most popular modern VR headsets is Google Cardboard that uses smartphones as its screen. When the smartphone is placed inside the 
glasses-like cardboard frame while running the Google Cardboard application, its screen is split into two sections that provide each eye a 360-degree field of view. The results are highly immersive VR experiences. instruments used in the case study were the Google Cardboard VR device, VirtualSpeech VR application, learning logs via Google Docs, surveys via SurveyMonkey, one-to-one interviews, and the researcher's fieldnotes.

\section{E. VirtualSpeech}

The study employed a VR program available for Google Cardboard called VirtualSpeech. VirtualSpeech is a VR mobile application that allows users to upload their PowerPoint presentations and then practice their delivery in a virtual reality environment (VRE) that includes a virtual audience. The audience does not interact with the user, nor do they provide feedback, but the application measures the talking time of its users and the extent of their eye contact with the virtual audience.
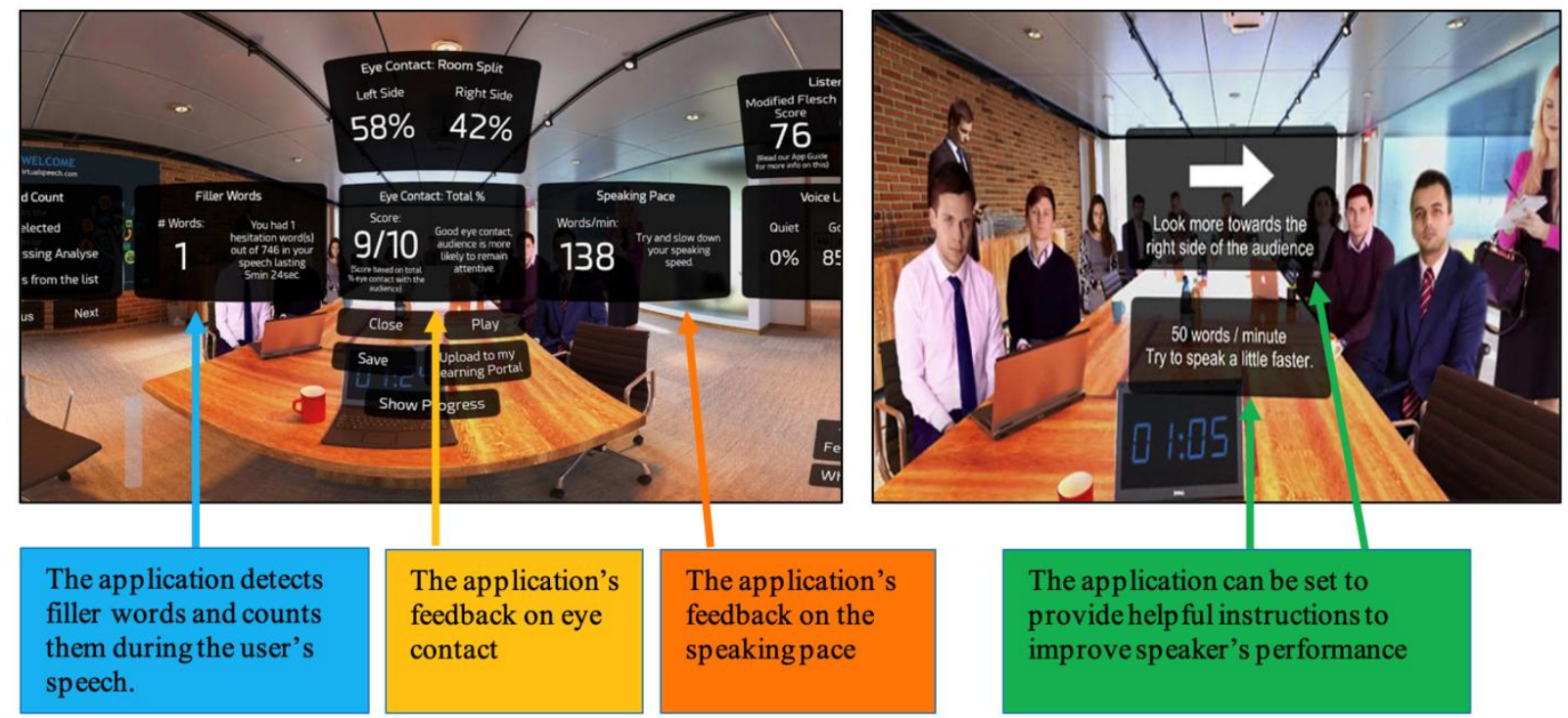

The application's feedback on eye contact
The application's feedback on the speaking pace
The application can be set to provide help ful instructions to improve speaker's performance

Figure 1: Screenshots from the virtual environment of VirtualSpeech with examples of its feedback

\section{F. Learning Logs}

The main aim of data collected from learning logs was to obtain students' perceptions of VirtualSpeech while preparing for oral presentations. The learning $\log s$ consisted of four open-ended questions and were privately shared with the student participants before the midterm presentation via Google Docs. The learning logs included prompts that encouraged students to write about their initial user experience of VirtualSpeech honestly. The following table consists of the learning log prompts:

TABLE I

LEARNING PROMPTS

\begin{tabular}{|l|l|}
\hline First question & In VirtualSpeech, how many different environments can you select from the menu to practice speaking? \\
\hline Second question & $\begin{array}{l}\text { In all of the different environments of VirtualSpeech, what are the people in the audience doing while you are } \\
\text { speaking? }\end{array}$ \\
\hline Third question & What was easy or difficult in using VirtualSpeech? \\
\hline Fourth question & What did you like or dislike about VirtualSpeech? \\
\hline
\end{tabular}

Additionally, a vital purpose of the learning logs was to distinguish the level of engagement of the student participants. A student's answers to the first two questions showcased if he/she had used VirtualSpeech and if he/she was writing genuine and credible responses for the study. Furthermore, the learning logs were utilized to answer the second research question; this is because the learning logs captured students' first impressions of using VirtualSpeech as a preparation tool for oral presentations.

\section{G. Surveys}

The surveys were retrospective, and they focused on eliciting opinions about the effectiveness of VirtualSpeech in oral presentation preparation. Two types of surveys were employed in this case study. The first type is student surveys, and the second type is an instructor survey. The student surveys (see Appendix A) were distributed after the midterm presentation, while the instructor survey (see Appendix B) was distributed at the end of the semester. Both surveys were distributed through SurveyMonkey and included a mixture of close-ended and open-ended questions. The surveys served to answer all of the research questions via opinion responses from all of the participants. 


\section{H. Structured Interviews}

Each student was interviewed after the last oral presentation. The interviews were audio-recorded and transcribed at the start of data analysis. The interview questions were scripted (see Appendix C), and certain questions from the learning logs and student surveys were repeated in the interviews. This is because the interview questions seek to find consistency in the students' answers in learning logs, surveys, and interviews. In addition, a significant purpose of the interviews is investigating the possibility that the student's progress in delivering oral presentations might be ascribed to tools other than VirtualSpeech. For instance, the fifth question of the interview, "Do you feel that you are now able to perform better in future presentations? Why?" is designed to elicit responses about all the methods and tools that helped the students without mentioning VirtualSpeech.

\section{Fieldnotes}

The researcher had attended the midterm and final presentations and wrote observations during the presentations. The researcher mainly focused on noting the emotional state of the presenters. The notes were built on the researcher's perception of how each student felt (e.g., calm, nervous) during his/her presentation. Moreover, these observations were used to contrast the students' answers on the surveys and interviews about their affect during the presentation.

\section{DATA ANALYSIS}

The data gathered from the four qualitative methods were analyzed to assess the effectiveness of VirtualSpeech in promoting positive learning outcomes and alleviating PSA. The analysis focused on the participants' attitudes toward VR technology. The following figure demonstrates a timeline for the data collection and analysis of this research.

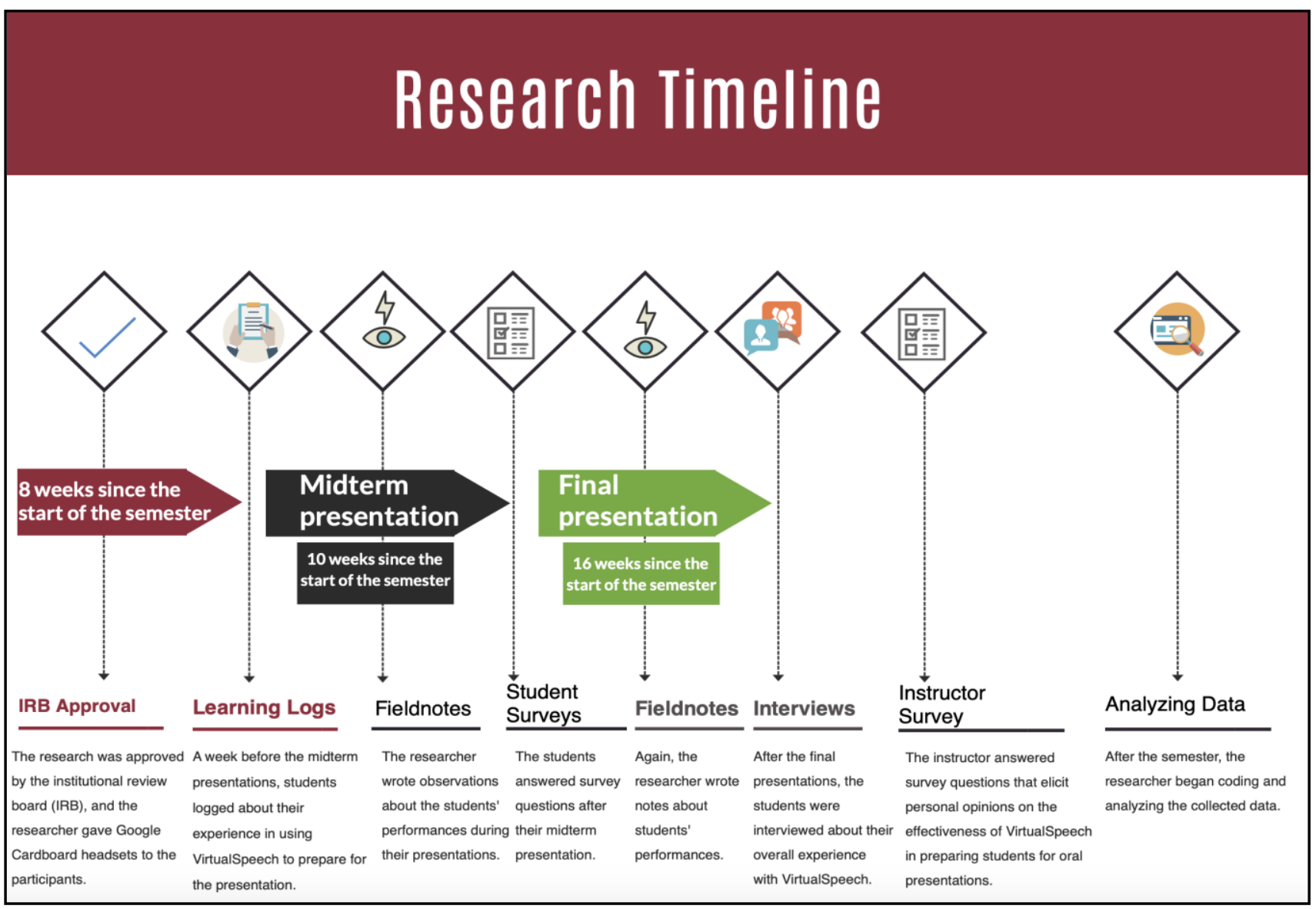

Figure 2: Research methodology timeline

\section{A. Learning Logs}

One of the main purposes of the learning logs was filtering genuine responders from non-genuine responders. Two students did not provide suitable answers to all the prompts of the learning log, as they provided incorrect and irrelevant answers. The researcher met the two students to discuss their answers because he had thought they misunderstood the prompts and found them to be vague. However, the researcher discovered that they lost their interest in participating in the study; consequently, there was a mutual understanding and agreement that they would withdraw their participation 
from the study. While reading the students' answers in the learning logs, the researcher created a table of two columns for positive and negative comments, and each column contained quotes from multiple participants.

\section{B. Surveys}

For student and instructor surveys, the researcher gathered data from open-ended questions in a non-linear pattern, as the researcher followed a grounded theory which is an approach described by Dey (2004) as a flexible data-analysis method without limiting guidelines. The grounded theory allows the researcher to have a theory as an outcome after data analysis (Dörnyei \& Csizér, 2012). Regarding closed-ended questions for student surveys, the researcher analyzed the responses by observing graphs generated from SurveyMonkey, and the researcher combined multiple graphs to create one comprehensive graph via Microsoft Excel. As for open-ended questions for student surveys, the researcher observed the students' written responses and highlighted keywords. Regarding the instructor's survey, the researcher analyzed responses for open- and closed-ended questions by identifying keywords.

\section{Structured Interviews}

The researcher included questions that were repeated from learning logs and surveys to test for consistency. The researcher grouped the 13 interview questions into two main sections. Questions 1-6 are about students' overall experience with oral presentations before and after enrolling in ENG 106, and questions 7-13 are about students' experience with VirtualSpeech in preparation for oral presentations. After transcribing the interviews, the researcher read the responses of each participant and identified keywords. Based on keywords, the researcher generated categories within the two main sections of the interviews (questions 1-6 and 7-13). Merriam (2009) named this method in data analysis as category construction for finding themes and patterns.

\section{Fieldnotes}

The fieldnotes mainly contained the researcher's personal observations of students' affect during the presentation and frequency of eye contact with the audience. The researcher color-coded specific words that refer to emotions and eye contact. The analyzed data from fieldnotes were utilized to contrast students' answers in the interview and surveys regarding their performance and affect in oral presentations.

\section{RESULTS}

\section{A. Learning Logs}

The learning logs highlighted accessibility issues with VirtualSpeech. Some respondents were unable to perform basic functions that had been covered in the demonstration of the application and the study, while another student mentioned eye strain and dizziness from prolonged use. Overall, opinions toward the application were similarly mixed, with specific pieces of negative feedback, including the relatively small set of features and the lack of interactivity with other users (as well as with the virtual audience).

\section{B. Student Survey}

The student survey showed results for the following three aspects: 1- Students' emotions during the midterm presentation. 2- Students' speaking difficulties in delivering presentations. 3- The possible ways that VirtualSpeech helped the students in overcoming their difficulties. Regarding students' emotions during the midterm presentation, their responses were combined to produce the following figure. Fig. 3 indicates that all students, with the exception of one student (P3), were feeling "nervous" at the start of the presentation and felt "relaxed" as they progressed through the presentation.

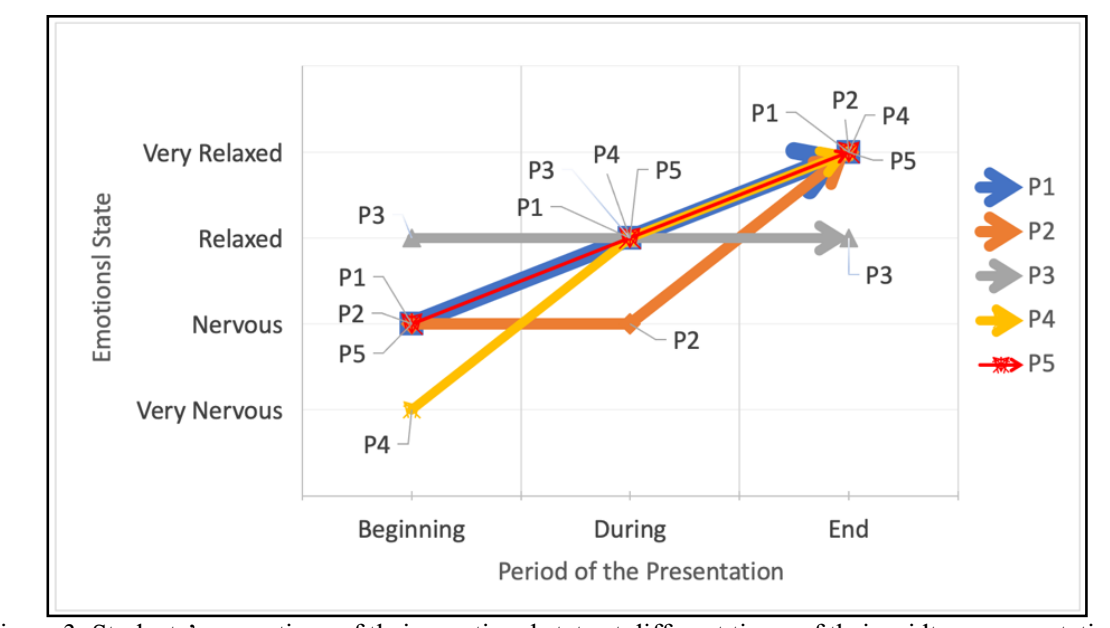

Figure 3: Students' perceptions of their emotional state at different times of their midterm presentations 
For the students' self-reported difficulties in delivering presentations, the students' answers were combined to produce the following table that indicates the type of difficulty and the number of students who reported having it.

TABLE II

STUDENTS' SELF-REPORTED DIFFICULTIES IN ORAL PRESENTATIONS

\begin{tabular}{|l|c|}
\hline Type of difficulty & Number of students who have it \\
\hline Lack of confidence & 2 out of 5 \\
\hline Lack of fluency & 5 out of 5 \\
\hline Lack of vocabulary & 1 out of 5 \\
\hline *Other difficulties & 2 out of 5 \\
\hline \multicolumn{2}{|c|}{ *The other difficulties: } \\
P1 said: "Not enough time" \\
P2 said: "Eye contact"
\end{tabular}

Regarding the helpfulness of VirtualSpeech in combating the difficulties, all of the students wrote positive comments about VirtualSpeech for the tenth question, "If VirtualSpeech had helped you then write how, and if it did not help you then also write how." However, only P1, P3, and P4 elaborated more on the benefits of VirtualSpeech. P1 and P4 expressed that VirtualSpeech helped them in gaining more confidence while presenting. Moreover, P3 said about VirtualSpeech that, "It makes us pay more attention to people which I like." This comment by P3 can relate to the difficulty of "eye contact."

\section{Instructor Survey}

The instructor thought that "lack of fluency" and "lack of vocabulary" were the most prominent difficulties that his students faced. Moreover, the instructor stated that the students' confidence in presenting had increased between the midterm and final presentation. However, the instructor said that this improvement could not certainly be attributed to VirtualSpeech, as the students had also received continuous training in delivering presentations. In addition, the instructor stated that VirtualSpeech needs to provide more types of specific feedback and include a feature that would allow instructors to monitor their students' progress in using the application.

\section{Structured Interviews}

The responses from the interviews showed results in students' opinions on the benefit of VirtualSpeech in reducing speaking anxiety and specific ways to improve the features of the application. All of the students, with the exception of P5, agreed that VirtualSpeech helped them in feeling less nervous during presentations. P2 and P3 elaborated more on this aspect by both saying that VirtualSpeech provides safe-fail virtual environments that simulate speaking in front of real people. However, P5 did not think that VirtualSpeech has a significant effect in reducing speaking anxiety because he thought that extensive practice for an upcoming presentation with or without VirtualSpeech would have the same effect in reducing the feeling of nervousness during a presentation. It is worthy to note that the students stated other components that significantly helped them in feeling less nervous for presentations, such as practicing for the presentation using their laptops, recording their presentation practice via a voice recorder application on their smartphones, and following notes given by the instructor and their peers. All of the students, with the exception of P3, provided suggestions to improve VirtualSpeech. P1 suggested that the program's developers need to create ways to remove the dizzy feeling she experienced when using it. P2 wanted more instructions inside the application that would increase its accessibility and effectiveness. P4 recommended that VirtualSpeech should have motion detection because he wanted the ability to move around during the presentation virtually. P5 thought that VirtualSpeech should not be limited to presentations, as he thought that the application should have more speaking activities such as virtual conversations with other users via the program's online connectivity.

\section{E. Fieldnotes}

The researcher's fieldnotes showed a significant degree of correlation between what the researcher had observed during students' presentations and what the students mentioned in their surveys and interviews about their levels of confidence during presentations. The researcher noted that all students, with the exception of P3, were nervous at the beginning of their presentations and became more relaxed towards the end of their presentations. Moreover, the researcher noted that students had improved in different aspects between the midterm and final presentation. For instance, in the final presentation, all of the students enhanced their presentation organization, and they improved their eye contact with the audience as they had gained more confidence in speaking towards the end of the course.

\section{DISCUSSION}

The results can be summarized in the following three aspects: (1) All of the participants saw a benefit for VirtualSpeech in reducing public speaking anxiety (PSA). (2) The user experience of the application varied among different students. This is because some students did not report any issues with VirtualSpeech, while other students reported difficulties in using the application. (3) Most of the participants provided suggestions that aim to enhance the user experience of VirtualSpeech and make it more beneficial in training to deliver presentations. 


\section{A. The Effects of VR Practice on Delivering Oral Presentations}

Between the midterm and final presentation, the results showed that students had decreased levels of nervousness; however, these positive results cannot be entirely attributed to VirtualSpeech. This is because students had received helpful feedback from fellow peers and their instructor. Still, the results included students' attribution to VirtualSpeech as one of the methods that improved their speaking confidence. Moreover, the most common feature that the students mentioned is the realistic classroom environment and the virtual audiences that made the students feel as if they were presenting in a real academic setting. Moreover, P2 stated that VirtualSpeech gave him a safe environment that allowed him to practice his presentations without feeling embarrassed in making mistakes. This particular finding supports claims made by researchers such as Ruggiero (2013) that virtual environments are fail-safe environments that encourage students to practice their target language without the fear of embarrassment when making language mistakes. Additionally, based on the difficulties chart (see Table II) and the interview data, it could be stated that all of the students attributed VirtualSpeech to overcoming at least one difficulty from the chart of presentation difficulties. P3, for instance, attributed his progress in pronunciation to the time spent practicing with VirtualSpeech, highlighting the recording function as particularly useful. These results suggest that the VR environment is maybe specifically helpful in making progress on issues of fluency and pronunciation. Moreover, P2 and P3 mentioned VirtualSpeech in relation to the "Eye contact" difficulty, and P3 said in the interview that he liked that VirtualSpeech measures eye contact level, as he thought that this feature is helpful in improving eye contact with real-life audiences.

\section{B. Variability in Student Experiences of VR}

Not all of the students had the same user experience with VirtualSpeech, as all of them experienced different negative and positive aspects of the program. As mentioned in the results, P5 saw the least benefit in using VirtualSpeech to improve speaking confidence. One of the possible reasons that explain P5's experience can be established from the timeline of the study (see Fig. 2), which shows that students had only two weeks to utilize VirtualSpeech for their midterm presentation. Thus, P5 may not have been able to devote adequate time to VirtualSpeech from the beginning of the study. P4 had a much different experience than P5, as P4 expressed that VirtualSpeech was a useful tool in increasing speaking confidence due to the program's focus on eye contact practice with virtual audiences. It is worthy to note that P4 had the highest levels of nervousness during his midterm presentation (see Fig. 3). This result matches the results of studies that found that virtual environments are most effective for users who possess high levels of anxiety. For example, Stupar-Rutenfrans et al. (2017) reported that Speech Trainer, which is a software application similar to VirtualSpeech, was most effective in reducing speaking anxiety for participants who suffered high levels of anxiety. In addition, the students' user experience differed in terms of encountered issues in using all of the features of VirtualSpeech. P3 expressed his use of the program's presentation recording feature without any issues or confusion; however, P2 and P5 experienced difficulties in fully utilizing the program's features. For instance, P2 did not identify the method of recording his presentation, and P5 was confused about the process of uploading presentations into the program. These difficulties may have been linked to the training provided at the beginning of the study, as retrospective interviews suggested that the training - which introduced the headsets and provided information on YouTube tutorials - did not go into sufficient depth in discussing key procedures, including recording and uploading presentations. Additionally, the study brought to light a negative user experience that might pose a potential challenge for future work in VR, which is nausea and eye discomfort that some participants can feel when using the headsets for extended periods of time. Only one participant, P1, mentioned these problems in this study, but they are common among VRET studies, such as Raghav et al. (2016) study on VR use to combat the anxiety and fear of dentists. One of the best ways to lessen these negative aspects is thorough and rigorous training on mitigation protocols, such as taking a frequent fifteen-minute break for every 30 minutes spent using the headset ("Virtual Reality Health \& Safety Usage Guide," n.d.).

\section{Implications for the Classroom}

The results demonstrate that instructors may recommend VR tools such as VirtualSpeech to support their students in practicing specific presentation skills, such as making and maintain eye contact with audiences. Moreover, in regard to public speaking anxiety (PSA), students who are especially anxious or nervous about presenting can and should absolutely be encouraged to use VR to practice. This is because VR allows students to practice delivering oral presentations in realistic and fail-safe environments, which is proven by researchers such as Stupar-Rutenfrans et al. (2017).

\section{Implications for the Developers of VirtualSpeech}

The students stated that the program should provide cues that improve the user's performance; for instance, VirtualSpeech should show indicators that constantly remind the user to keep eye contact with the virtual audiences and not focus on a single direction. This suggestion can directly help improve a user's eye contact level while delivering a presentation, rather than only learning about the statistical data regarding a user's eye contact at the end of his/her talk. Additionally, both the instructor and the students mentioned that VirtualSpeech lacked interaction and lacked a feature that allows the teacher to check on his/her students' performances. Regarding the lack of interaction between the user and the virtual audiences, this is based on the limited technological resources of the Google Cardboard VR headset. A 
virtual audience that can comprehend the content of the user's presentation and has the ability to give specific feedback on it might be possible; however, this could be achieved with the advancement of artificial intelligence (AI) that would be programmed for the virtual audiences. Moreover, there is another possible method that allows users to receive interaction from the virtual audiences without AI, which is adding a feature that allows other users to join the presentation and interact with the presenter. This feature would require online connectivity and would also be incredibly beneficial for the instructor to view and evaluate his/her students while using VirtualSpeech.

\section{E. Limitations}

Although the research is a case study, the timeline of the case study was limited and did not allow for further data collection, especially with the instructor. In addition, the main limitation of the study was the curriculum of the course (ENG 106 -Academic Oral Communication Skills). This is because the primary objective of the course was to generally develop students' speaking skills via listening activities, discussions, and two presentations. Consequently, the study included a limited number of presentations that were observed and analyzed.

\section{F. Directions of Further Research}

A key recommendation is to conduct the study in a course dedicated to presentation skills, as the researchers would have more extensive data to validate the use of VR applications such as VirtualSpeech for participants who struggle in delivering oral presentations. Moreover, another recommendation is to adopt a longer timeline with longer periods allocated to increasing participants' familiarization with all of the available features of the VR software, as participants who are more comfortable with the VR tool and its capabilities will better be able to leverage it to augment their learning. Lastly, it would be incredibly advantageous for researchers to conduct this study with a larger group sample, and they should collaborate with the instructor to design a presentation rubric that evaluates students' progress in overcoming difficulties, such as the ones mentioned in Table II, and this rubric would also assess skills that software applications such as VirtualSpeech claim to develop.

\section{CONCLUSION}

The present study explored the use of the VirtualSpeech VR mobile application for practicing public speaking in a college-level ELL course. The experiences of student participants were collected through one-on-one structured interviews, surveys, and learning logs, complemented by fieldnotes. Questions and prompts focused on challenges encountered with the software, positive effects on anxiety or nervousness and vocabulary, fluency, and other aspects of speech performance, and on general attitudes toward the VR platform.

The results were encouraging with respect to the future of VR as a means of helping students cope with PSA and other barriers to language learning. All participants reported that the use of a virtual practice space in addition to athome and in-class learning and practice had an overall positive effect. Most said that it helped with feelings of nervousness; most said that it helped them in feeling more confident. Some participants' experiences raised the possibility, which is supported by the literature, that those whose PSA is particularly acute may benefit from the "safe" practice space created by VR more than their less-anxious peers. In addition, while the details varied, all of the students agreed that the virtual practice had also helped them overcome at least one significant barrier to delivering their oral presentations successfully. There were a number of minor difficulties in the implementation and use of the platform; however, these would likely be easily remedied by more in-depth training, longer periods for familiarization, and more thorough incorporation of the VRE into classroom activities and homework assignments.

Participants also had a number of detailed and specific suggestions for improvements that might be made to the virtual space in order to better facilitate language learning. Social features were mentioned most often, including sharing of recorded presentations, tools for giving feedback and comments, and general communication options. Some students also felt that a more immersive and interactive virtual environment would be more realistic and more effective, although the suggestions offered might be beyond the capabilities of the Google Cardboard VR setup.

These results point toward a need for meaningful additional research. Future work should experiment with other more fully-featured VR platforms and technologies, and it should be administered in contexts where VR can become a more central part of the curriculum. The potential gains are significant: many students suffer from some form of anxiety related to public speaking or even just speaking up at all in foreign language classes. Given the global reach and significance of English as a second language, a low-cost and accessible software tool that allows students to confront PSA safely and comfortably has the potential to be a game-changer in language education. 
Appendix A. Template of the Student Survey

$* 1$. What is your gender?

$\square$ Female

$\square$ Male

$\square$ And what is your age?

*2. How much time did you spend in preparation for the presentation?

Less than 1 hour

1-2 hours

3 hours or more

* 3. How did you feel at the beginning moments of your presentation?

Very Nervous

Nervous

Relaxed

Very Relaxed

Other (please specify)

* 4. How did you feel during your presentation?

Very Nervous

Nervous

Relaxed

Very Relaxed

Other (please specify)

* 5. How did you feel at the end of your presentation?

Very Nervous

Nervous

Relaxed

Very Relaxed

Other (please specify) 
*6. How would you rate the performance of your presentation?
Very Bad
Good
$\bigcirc \mathrm{Bad}$
Very Good
Mediocre
Other (please specify)

* 7. Did you encounter any difficulties while doing the presentation?

$\bigcirc$ Yes

No (Skip the next question)

8. What might have been a difficulty that you have faced during your presentation? (check all boxes that apply)

$\square$ Lack of confidence (ie. shyness, facing anxiety and fear when speaking)

Lack of fluency (fluency is the ability to speak the language with complete ease and with complete accuracy, which also means speaking the language without making mistakes in pronunciation)

$\square$ Lack of vocabulary knowledge

Other difficulties (please specify)

* 9. Has VirtualSpeech helped you in preparing for your presentation?

Yes

No

* 10. If Virtualspeech had helped you then write how, and if it did not help you then also write how: 


\section{APPENDIX B. TEMPLATE OF THE ISTRUCTOR SURVEY}

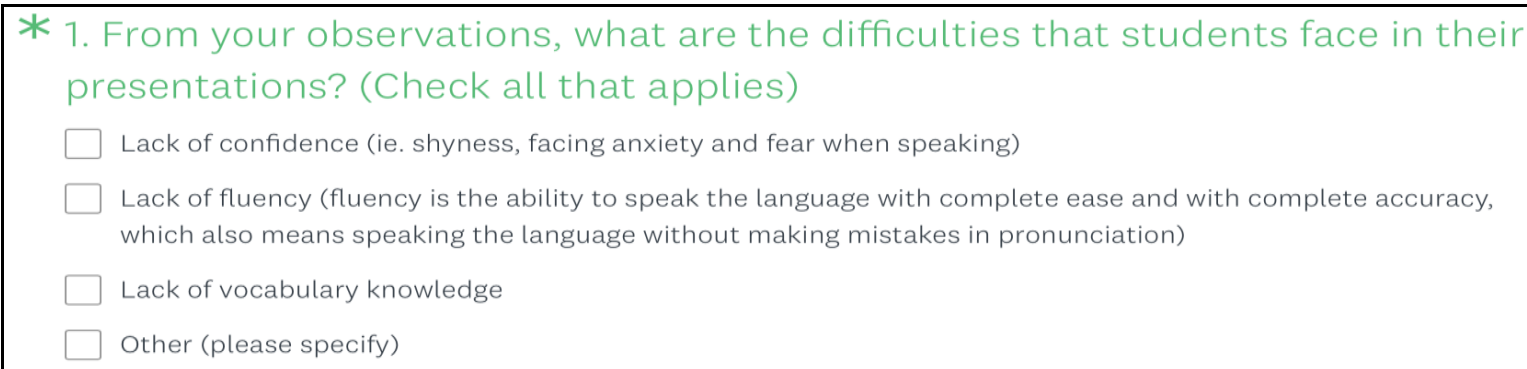

* 2. How helpful do you think Virtualspeech is in preparing students for their presentations?

$\bigcirc$ Extremely helpful $\bigcirc$ Not so helpful

Very helpful

Not at all helpful

Somewhat helpful

* 3. What are the reasons for your answer to the previous question (helpfulness of VR)

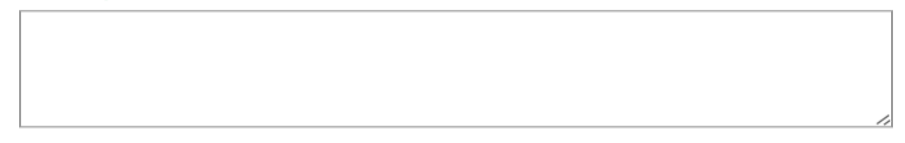

* 4. Would you recommend using Virtualspeech for future students?

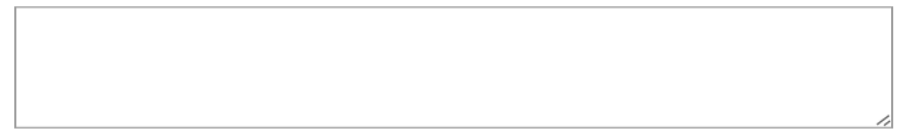

* 5. Do you think Virtualspeech can be improved for students practicing upcoming presentations?

No

Yes (please specify your opinion on improvements of this technology)

comments or judgments regarding the topic of VR in preparing students for oral presentations. 


\section{APPENDix C. SCRIPTED INTERVIEW QUESTIONS FOR PARTICIPATING STUDENTS}

Q1- How did you feel during your last presentations?

Q2- Do you think you have done better at the final presentation than any of the previous presentations?

Q3- How did you prepare for presentations before you took ENG 106?

Q4- Did you like doing presentations before you took this class? Why?

Q5- Do you feel that you are now able to perform better in future presentations? Why?

Q6- Would you change anything about your performance in the last presentation?

Q7- Were you aware of virtual reality headsets before I provided you with a Google Cardboard VR headset?

Q8- What did you think of VirtualSpeech when you first started using it?

Q9- What do you think of VirtualSpeech now?

Q10- Has VirtualSpeech helped you in feeling less nervous in doing presentations? Explain if it did or didn't.

Q11- Did you use other tools than VirtualSpeech in preparing for your presentations? What are they?

Q12- Would you recommend other students to use VirtualSpeech in preparation for doing presentations? If yes or no, why?

Q13- What do you think should be added to VirtualSpeech to improve it for you and for other students?

\section{ACKNOWLEDGMENTS}

This article is derived from the author's graduate thesis that was submitted as a requirement for the fulfillment of the degree of Master of Arts in Teaching English to Speakers of Other Languages. Dr. Benjamin White was the thesis advisor and provided feedback on the original paper. Moreover, this study did not receive any type of funding and no potential conflict of interest is reported by the author.

\section{REFERENCES}

[1] About VirtualSpeech. (n.d.). Retrieved June 3, 2021, from VirtualSpeech website: https://virtualspeech.com/about

[2] Ang, C. S., \& Rao, G. R. K. (2008). Computer game theories for designing motivating educational software: A survey study. International Journal on E-Learning, 7(2), 181-199.

[3] Banks, J., Carson, J. S., Nelson, B. L., \& Nicol, D. M. (2001). Verification and validation of simulation models. Discrete-event system simulation (3rd ed.). Upper Saddle River, NJ: Prentice-Hall

[4] Beck, J. S. (2011). Cognitive behavior therapy: Basics and beyond (2nd ed.). New York, NY: Guilford Press.

[5] Beckman, W. S. (2009). Pilot perspective on the Microsoft Flight Simulator for instrument training and proficiency. International Journal of Applied Aviation Studies, 9(2), 171-180.

[6] Brundage, S. B., \& Hancock, A. B. (2015). Real enough: Using virtual public speaking environments to evoke feelings and behaviors targeted in stuttering assessment and treatment. American Journal of Speech-Language Pathology, 24(2), 139-149.

[7] Burns, A., \& Joyce, H. (1997). Focus on speaking. New South Wales, Australia: National Centre for English Language Teaching and Research.

[8] Bygate, M. (1987). Speaking. New York, NY: Oxford University Press.

[9] Chen, Y. L., \& Hsu, C. C. (2020). Self-regulated mobile game-based English learning in a virtual reality environment. Computers \& Education, 154, 103910. doi:10.1016/j.compedu.2020.103910

[10] Cheng, A., Yang, L., \& Andersen, E. (2017). Teaching language and culture with a virtual reality game. Proceedings of the 2017 CHI Conference on Human Factors in Computing Systems - CHI '17. doi:10.1145/3025453.3025857

[11] Dey, I. (2004). Grounded theory. In Seale, C., Gobo, G., Gubrium, J. F., \& Silverman, D. (Eds.), Qualitative research practice (pp. 80-93). London: Sage.

[12] Dörnyei, Z., \& Csizér, K. (2012). How to design and analyze surveys in second language acquisition research. In A. Mackey \& S. M. Gass (Eds.), Research methods in second language acquisition: A practical guide (pp. 74-94). Malden, MA: WileyBlackwell. doi:10.1002/9781444347340.ch5

[13] Frisby, B. N., Kaufmann, R., Vallade, J. I., Frey, T. K., \& Martin, J. C. (2020). Using virtual reality for speech rehearsals: An innovative instructor approach to enhance student public speaking efficacy. Basic Communication Course Annual, $32(1), 6$.

[14] Gee, J. P. (2003). What video games have to teach us about learning and literacy. Computers in Entertainment, 1(1), 20. doi:10.1145/950566.950595

[15] Gee, J. P. (2007). Good video games plus good learning. Bern, Switzerland: Peter Lang.

[16] Harmer, J. (2007). The practice of English language teaching (4th ed.). Harlow: Pearson Education Limited.

[17] Harris, D. P. (1969). Testing English as a second language. New York, NY: McGraw-Hill College.

[18] Harris, S. R., Kemmerling, R. L., \& North, M. M. (2002). Brief virtual reality therapy for public speaking anxiety. CyberPsychology \& Behavior, 5(6), 543-550. doi:10.1089/109493102321018187

[19] Hinojo-Lucena, F. J., Aznar-Díaz, I., Cáceres-Reche, M. P., Trujillo-Torres, J. M., \& Romero-Rodríguez, J. M. (2020). Virtual reality treatment for public speaking anxiety in students. Advancements and results in personalized medicine. Journal of personalized medicine, 10(1), 14. doi:10.3390/jpm10010014

[20] Hsiao, I. Y., Lan, Y. J., Kao, C. L., \& Li, P. (2017). Visualization analytics for second language vocabulary learning in virtual worlds. Journal of Educational Technology \& Society, 20(2), 161-175.

[21] Hyland, K. (1991). Developing oral presentation skills. English Teaching Forum, 29(2), 35-37

[22] Immordino-Yang, M. H. (2015). Emotions, learning, and the brain: Exploring the educational implications of affective neuroscience (Norton series on the social neuroscience of education). New York, NY: W. W. Norton \& Company. 
[23] King, J. (2002). Preparing EFL learners for oral presentations. Internet TESL Journal, 8(3). Retrieved June 11, 2021, from http://iteslj.org/Lessons/King-PublicSpeaking

[24] Kirriemuir, J., \& McFarlane, A. E. (2003). Literature review in games and learning. Bristol, England: Nesta Futurelab.

[25] Li, K. C., \& Wong, B. T. M. (2021). A literature review of augmented reality, virtual reality, and mixed reality in language learning. International Journal of Mobile Learning and Organisation, 15(2), 164-178. doi:10.1504/IJMLO.2021.114516

[26] Lin, T. J., \& Lan, Y. J. (2015). Language learning in virtual reality environments: Past, present, and future. Journal of Educational Technology \& Society, 18(4), 486-497.

[27] Linden Lab (2003). Second Life [Computer software]. Retrieved June 11, 2021, from https://secondlife.com/support/downloads/

[28] Lindner, P., Dagöö, J., Hamilton, W., Miloff, A., Andersson, G., Schill, A., \& Carlbring, P. (2021). Virtual Reality exposure therapy for public speaking anxiety in routine care: a single-subject effectiveness trial. Cognitive Behaviour Therapy, 50(1), 6787. doi:10.1080/16506073.2020.1795240

[29] Merchant, Z., Goetz, E. T., Cifuentes, L., Keeney-Kennicutt, W., \& Davis, T. J. (2014). Effectiveness of virtual reality-based instruction on students' learning outcomes in K-12 and higher education: A meta-analysis. Computers \& Education, 70, 29-40. doi:10.1016/j.compedu.2013.07.033

[30] Merriman, S. B. (2009). Qualitative research: A guide to design and implementation. San Francisco, CA: Jossey-Bass

[31] Molla, R. (2017, April 28). Vox Media. Retrieved January 15, 2021, from https://www.vox.com/2017/4/28/15376268/facebookaugmented-virtual-reality-linkedin-jobs-charts

[32] Morrison, R. (2016). Virtual reality in the language learning classroom. The Morning Watch: Educational and Social Analysis, 44(1-2). Retrieved January 10, 2021, from https://journals.library.mun.ca/ojs/index.php/mwatch/article/view/1743

[33] Myers, K. M., \& Davis, M. (2007). Mechanisms of fear extinction. Molecular Psychiatry, 12(2), 120-150.

[34] Nation, I., \& Newton, J. (2008). Teaching ESL/EFL listening and speaking. London, England: Routledge.

[35] Olle, D., \& Westcott, J. R. (2018). Video game addiction. Herndon, VA: Stylus Publishing, LLC.

[36] Opriş, D., Pintea, S., García-Palacios, A., Botella, C., Szamosközi, Ş., \& David, D. (2012). Virtual reality exposure therapy in anxiety disorders: a quantitative meta-analysis. Depression and Anxiety, 29(2), 85-93.

[37] Otte, C. (2011). Cognitive behavioral therapy in anxiety disorders: Current state of the evidence. Dialogues in Clinical Neuroscience, 13(4), 413-421.

[38] Owens, M. E., \& Beidel, D. C. (2015). Can virtual reality effectively elicit distress associated with social anxiety disorder ?. Journal of Psychopathology and Behavioral Assessment, 37(2), 296-305.

[39] Page, E., \& Smith, R. (1998). Introduction to military training simulation: A guide for discrete event simulationists. 1998 Winter Simulation Conference. Proceedings (Cat. No.98CH36274). doi:10.1109/wsc.1998.744899

[40] Parkinson, B., Totterdell, P., Briner, R. B., \& Reynolds, S. A. (1996). Changing moods: The psychology of mood and mood regulation. Boston, MA: Addison-Wesley Longman.

[41] Pavlenko, A. (2011). Thinking and speaking in two languages. Bristol, United Kingdom: Multilingual Matters.

[42] Pekrun, R., Goetz, T., Titz, W., \& Perry, R. P. (2002). Academic emotions in students' self-regulated learning and achievement: A program of qualitative and quantitative research. Educational Psychologist, 37(2), 91-105. doi:10.1207/s15326985ep3702_4

[43] Pertaub, D., Slater, M., \& Barker, C. (2002). An experiment on public speaking anxiety in response to three different types of virtual audience. Presence: Teleoperators and Virtual Environments, 11(1), 68-78. doi:10.1162/105474602317343668

[44] Powers, M. B., \& Emmelkamp, P. M. (2008). Virtual reality exposure therapy for anxiety disorders: A meta-analysis. Journal of Anxiety Disorders, 22(3), 561-569.

[45] Raghav, K., Van Wijk, A. J., Abdullah, F., Islam, M. N., Bernatchez, M., \& De Jongh, A. (2016). Efficacy of virtual reality exposure therapy for treatment of dental phobia: A randomized control trial. BMC oral health, 16(1), 1-11. doi:10.1186/s12903-016-0186-Z

[46] Reinders, H. (Ed.). (2012). Digital games in language learning and teaching. London, England: Palgrave Macmillan.

[47] Ruggiero, D. (2013). Video games in the classroom: The teacher point of view. Paper presented at the Games for Learning workshop of the Foundations of Digital Games conference, Chania, Greece.

[48] Ruscio, A. M., Brown, T. A., Chiu, W. T., Sareen, J., Stein, M. B., \& Kessler, R. C. (2008). Social fears and social phobia in the USA: Results from the National Comorbidity Survey Replication. Psychological Medicine, 38(1), 15-28.

[49] Samsung Electronics (2016). Be Fearless: Fear of Public Speaking (Version 2.5.0) [Mobile application software]. Retrieved January 9, 2021, from https://www.oculus.com/experiences/gear-vr/942681562482500/

[50] Schroeder, R. (1996). Possible worlds. Boulder, CO: Westview Press.

[51] Stupar-Rutenfrans, S., Ketelaars, L. E., \& van Gisbergen, M. S. (2017). Beat the fear of public speaking: Mobile 360 video virtual reality exposure training in home environment reduces public speaking anxiety. Cyberpsychology, Behavior, and Social Networking, 20(10), 624-633.

[52] Syakur, M. (1987). Language testing. Surakarta: UNS Press.

[53] Symonenko, S., Zaitseva, N., Osadchyi, V., Osadcha, K., \& Shmeltser, E. (2020). Virtual reality in foreign language training at higher educational institutions.

[54] Thornbury, S. (2005). How to teach speaking. Harlow: Longman.

[55] Tobias, S., Fletcher, J. D., \& Wind, A. P. (2014). Game-based learning. In M. Spector, M. D. Merrill, J. Elen, \& M. J. Bishop (Eds.), Handbook of research on educational and communications technology (pp. 485-504). New York, NY: Springer Academic.

[56] Virtual Reality Health \& Safety Usage Guide. (n.d.). Retrieved June 10, 2020, from ClassVR website: https://www.classvr.com/health-and-safety/

[57] VirtualSpeech Ltd. (2018). VirtualSpeech (Version 1.75) [Mobile application software]. Retrieved January 9, 2021, from https://virtualspeech.com/download-app

[58] Wallach, H. S., Safir, M. P., \& Bar-Zvi, M. (2009). Virtual reality cognitive behavior therapy for public speaking anxiety: A randomized clinical trial. Behavior Modification, 33(3), 314-338. 
[59] Wolf In Motion Ltd. (2016). Speech Trainer [Computer software]. Retrieved January 9, 2021, from https://store.steampowered.com/app/552770/Speech_Trainer/

[60] Woodrow, L. (2006). Anxiety and speaking English as a second language. RELC Journal, 37(3), 308-328. doi:10.1177/0033688206071315

[61] Young, M., Slota, S., Cutter, A., Jalette, G., Mullin, G., \& Lai, B. et al. (2012). Our princess is in another castle. Review of Educational Research, 82(1), 61-89. doi:10.3102/0034654312436980

Mohamed Jameel Alsaffar is an M.A in TESOL graduate from Saint Michael's College, Vermont, USA. His area of research interest is the utilization of modern technologies in English language acquisition, specifically the fields of computer-assisted language learning and mobile-assisted language learning. Mohamed is reachable by email: mjihassan@gmail.com 